Bangladesh Rice J. 22 (1) : 65-72, 2018

\title{
Stability and Adaptability Analysis of BRRI Developed Aus Varieties in Different Locations of Bangladesh
}

\author{
N M F Rahman ${ }^{1 *}$, M A A Mamun¹, R Ahmed1, M I Hossain¹, M A Qayum¹, M A Aziz¹, \\ M A Hossain ${ }^{2}$ and M S Kabir ${ }^{1}$
}

\begin{abstract}
The genotype by environment $(\mathrm{G} \times \mathrm{E})$ interactions can be observed by differential genotypic responses to varied environmental conditions. Its effect is to limit the accuracy of yield estimates and complicate the identification of specific genotypes for specific environments. The frequently used model additive main effects and multiplicative interaction (AMMI) were used in this study to identify high yielding Aus rice varieties having wide adaptation and or specific adaptation to environment. Multi environment trials on eight Aus rice varieties were conducted at four environmental conditions in 2016. Genotype by environment $(G \times E)$ interactions contribution was much higher than the genotypic effect and environmental effect on grain yield. The genotypes BRRI dhan65, BRRI dhan48 and BRRI dhan43 display higher adaptability and stability. Therefore they are included in the study and recommended to be used in all environments. The variety BRRI dhan65 was identified as the most suitable variety with wider adaptability in the region Kushtia followed by BRRI dhan 48 and BRRI dhan43. Latest varieties performed better than the oldest ones based on grain yield and could be replaced through ensuring the supply chain of new promising varieties of that locality.
\end{abstract}

Key words: AMMI model, Aus rice varieties, $G \times$ E interaction and stability.

\section{INTRODUCTION}

Agro-based developing country like Bangladesh is striving hard for rapid development of its economy. The economic development of the country is mainly based on agriculture. The total cultivable area in Bangladesh is about $8.58 \mathrm{Mha}$ and net cultivated area is 7.95 Mha and 0.22 Mha are cultivable waste (Agriculture Diary 2018). The contribution of agriculture sector in GDP is 14.23 percent in 2017-18. The crop sub-sector dominates with $7.51 \%$ of total GDP at constant market price from which rice contributes $46 \%$ (National Accounts Statistics 2018). Of all crops, rice plays the leading role by contributing $96 \%$ of total food grain production (Bangladesh Food Situation Report 2018). Three major rice crops namely, Aus, Aman and Boro constitute $100 \%$ of total rice production and grow in three different seasons. The Aus rice is important crop for drought prone, low water requiring environments in Bangladesh. Also transplanting cost is one of the major resource-consuming activities and it could be reduced through cultivating direct-seeded rice (DSR-Aus). There are two types of Aus rice such as Broadcast/direct seeded Aus also known as upland Aus and partially irrigated Aus or Transplanted Aus (TPR-Aus) in Bangladesh. Aus is typically planted in March-April and harvested in June-July and practically harmonized with the climatic season hot summer (March-May). Aus rice occupies about $12.53 \%$ of total cultivable area from where modern varieties cover $10.67 \%$ and local varieties cover $1.86 \%$. About $7.49 \%$ of total production comes from Aus rice where

${ }^{1}$ Bangladesh Rice Research Institute, Gazipur 1701, Bangladesh. 2Bangladesh Meteorological Department, Dhaka, Bangladesh. *Corresponding author's E-mail : niaz.sust@gmail.com 
modern varieties cover $6.87 \%$ and local varieties cover $0.62 \%$. The present status of total area and production of Aus rice is 1.08 million ha and 2.71 million MT (BBS, 2018). Research on adaptability of the Aus rice varieties would help farmers to cultivate right varieties in right area as well as the policy makers to formulate decision in this regard.

Genotype $\times$ environment (GE) interaction is an important issue faced by plant breeders in crop breeding programme. $\mathrm{G} \times \mathrm{E}$ interactions greatly affect the phenotype of a variety, so the stability analysis is required to characterize the performance of varieties in different environments, to help plant breeders in selecting varieties. Instability is the result of cultivars response in different environments which usually indicates a high interaction between genetic and environmental factors (Lone et al., 2009). Grain yield depends on genotype, environment and management practices and their interaction with each other (Messina et al., 2009). Under the same management conditions, variation in grain yield is principally explained by the effects of genotype and environment (Dingkuhn et al., 2006). Interactions between these two explanatory variables give insight for identifying genotype suitable for specific environments. The environmental effect is typically a large contributor to total variation (Blanche et al., 2009). Lestari et al. (2010) reported that there was significant difference between stability and adaptability of 35 aromatic new plant type rice lines across different environments. Similarly, Sreedhar et al. (2011), evaluate 60 hybrid rice cultivars for yield and its component stability across three different agro-climatic zones, and also found that stability in single plant yield was due to plasticity and stability in yield components. In the study of Mosavi (2013) in some promising rice genotypes showed highly significant yield differences among rice genotypes, environment and genotype by environment interaction. Some rice genotypes were adjudged stable when different yield stability parameters were considered. From Hasan (2014) study, GE interaction patterns revealed by AMMI biplot analysis indicated that the hybrid rice genotypes are broadly adapted. Genotypes Jin23A/PR344R, BRRI11A/AGR and IR79156A/BRRI20R showing high yield performance and widely adapted to all environments. Among the hybrids BRRI 10A/BRRI 12R, BRRI 9A/BRRI 15R, BRRI hybrid dhan2, BRRI dhan28 and BRRI dhan29 were found highly stable across the environments. BRRI 10A/BRRI 12R, BRRI 9A/BRRI 15R, II32A/BRRI 15R, II32A/BRRI 10R and BRRI hybrid dhan3 are highly stable as well as high yielder Kulsum (2014). BRRI hybrid dhan 2 is also the highest yielder and stable across environment. Several methods of measuring and describing genotypic response across environments have been developed and utilized. For this purpose, multi-location trials, over a number of years are conducted (Luthra et al., 1974).

AMMI model is a hybrid model involving both additive and multiplicative components of two way data structure with biplot facility. The AMMI model uses analysis of variance (ANOVA, an additive model) to characterize genotype and environment main effects and principal component analysis (a multiplicative model) to characterize their interactions (IPCA). The AMMI analysis has been shown to be effective. It captures a large portion of the GE sum of squares, clearly separating the main and interaction effects; and the model often provides an agronomically meaningful interpretation of the data (Gauch et al., 1992). AMMI analysis AMMI 1 biplot showed the genotypes HS-273, Heera-2, ACI-2 and HRM02 were highly stable with moderate yield potential but the genotype ACI93024 was more adapted to a wide range of environment than the rest of the genotypes, while BRRI 
dhan28 indices the lowest stability (Kulsum, 2015). Yield data were analyzed to determine the nature and magnitude of $G \times E$ interaction effects on grain yield in diverse environments. The multivariate approach, the AMMI model is better for partitioning the $G \times E$ into the causes of variation, which is easier to identify environments' potential and used to identify superior genotypes either specific adaptation or wide adaptation. The goal of this study was to evaluate the $\mathrm{G} \times \mathrm{E}$ interaction using AMMI biplot analysis for the grain yield of Aus rice varieties, in order to identify adaptable and stable varieties in different conditions.

\section{MATERIALS AND METHODS}

\section{Plant materials and experimental design}

Bangladesh Rice Research Institute (BRRI) has developed eight Aus rice varieties for both DSR and TPR-Aus ecosystem. These varieties are early, and growth duration and yield ranges from 99-115 days and 3.0-5.5 t ha-1 ${ }^{-1}$ respectively, with mostly high amylose content (> 25.0\%) except BR26 (22.7\%) which is preferable trait in the country (Table 1). This shorter duration varieties can also fit in the cropping pattern to increase cropping intensity. In this experiment BRRI released eight rice varieties were tested in four different environmental conditions of Bangladesh during the cropping season Aus 2016. Table 2 shows the description of the four environmental conditions, Gazipur (E1),
Kushtia (E2), Rajshahi (E3) and Rangpur (E4).

In each environment, the experiment was carried out in a randomized complete block design, with three replications. Each experimental plot was comprised of $10 \mathrm{~m}^{2}$ (10 rows, $5 \mathrm{~m}$ long, with $20 \mathrm{~cm}$ row spacing). Twenty-five-day-old seedlings were transplanted using two seedlings per hill. Standard management practices and plant protection measures were followed for each location as required following the recommendation of Adhunik Dhaner Chash, BRRI (2018). Two border rows were used to minimize the border effects. Data were collected on grain yield (tha-1) and $R$ programming language was used for analysis.

\section{Statistical analysis}

The combined analysis of variance and Additive Main and Multiplicative Interaction model were performed to look at $\mathrm{G} \times \mathrm{E}$ of the genotypes across all environments. AMMI uses ANOVA to analyze the main effects (additive part) and Principal Component Analysis (PCA) to analyze the non-additive residuals by the ANOVA (Gauch, 1993). The factor explained (\%) was calculated comparing sum of square (SS) from AMMI ANOVA. When a genotype and environment have the same sign on their respective first PCA axis, their interaction is positive, if different, their interaction is negative (Tariku et al., 2013).

Table 1. Phenotypic features of different traits of released Aus rice varieties in Bangladesh (BRRI, 2017).

\begin{tabular}{cccccccc}
\hline Variety & $\begin{array}{c}\text { Genotype } \\
\text { code }\end{array}$ & $\begin{array}{c}\text { Growth } \\
\text { duration (day) }\end{array}$ & $\begin{array}{c}\text { Plant height } \\
(\mathrm{cm})\end{array}$ & $\begin{array}{c}\text { Grain } \\
\text { shape }\end{array}$ & $\begin{array}{c}\text { Amylose } \\
(\%)\end{array}$ & $\begin{array}{c}\text { Yield } \\
\left(\text { tha }^{-1}\right)\end{array}$ & $\begin{array}{c}\text { Year of } \\
\text { release }\end{array}$ \\
\hline BR21 & G1 & 110 & 100 & MB & 25 & 3.0 & 1986 \\
BR24 & G2 & 105 & 105 & LS & 26 & 3.5 & 1992 \\
BR26 & G3 & 115 & 115 & LS & 22.7 & 4.0 & 1993 \\
BRRI dhan27 & G4 & 115 & 140 & MB & 27.5 & 4.0 & 1994 \\
BRRI dhan42 & G5 & 100 & 100 & LS & 26.1 & 3.5 & 2004 \\
BRRI dhan43 & G6 & 100 & 100 & MS & 26.7 & 3.5 & 2004 \\
BRRI dhan48 & G7 & 110 & 105 & MB & 26.8 & 5.5 & 2008 \\
BRRI dhan65 & G8 & 99 & 88 & MS & 26.8 & 3.5 & 2014 \\
\hline
\end{tabular}

$\mathrm{MB}=$ medium bold, $\mathrm{MS}=$ medium slender and $\mathrm{LS}=$ long slender. 
Table 2. Agro-ecological conditions of different experimental locations (BBS and BMD, 2016).

\begin{tabular}{ccccccc}
\hline & \multicolumn{5}{c}{ Agro-ecological condition } \\
\cline { 2 - 7 } Location & Latitude & Longitude & Altitude & $\begin{array}{c}\text { Annual rainfall } \\
(\mathrm{mm})\end{array}$ & $\begin{array}{c}\text { Mean maximum } \\
\text { temperature }\left({ }^{\circ} \mathrm{C}\right)\end{array}$ & $\begin{array}{c}\text { Mean minimum } \\
\text { temperature }\left({ }^{\circ} \mathrm{C}\right)\end{array}$ \\
\hline Gazipur & 23.99 & 90.41 & 15 & 745 & 33.87 & 25.88 \\
Khustia & 23.90 & 89.14 & 17 & 513 & 35.26 & 24.88 \\
Rajshahi & 24.37 & 88.66 & 20 & 689 & 35.50 & 24.60 \\
Rangpur & 25.70 & 89.27 & 35 & 1165 & 32.22 & 22.80 \\
\hline
\end{tabular}

The Additive Main and Multiplicative Interaction (AMMI) model

The AMMI model, which combines standard analysis of variance with PC analysis (Zobel et al., 1988), was used to investigate $\mathrm{G} \times \mathrm{E}$ interaction. In AMMI model the contribution of each genotype and each environment to the GEI is assessed by use of the biplot graph display in which yield means are plotted against the scores of the IPCA1 (Zobel et al., 1988).

The AMMI model is:

$Y_{g e}=\mu+\alpha_{g}+\beta_{e}+\sum_{n=1}^{N} \lambda n \gamma_{g n} \delta_{e n}+\rho_{g e}$

Where, $Y_{g e}=$ yield of the genotype (g) in the environments (e); $\mu=$ grand mean; $\alpha_{g}=$ genotype mean deviation; $\beta_{e}=$ environment mean deviation; $\mathrm{N}=$ no. of IPCAs (Interaction Principal Component Axis) retained in the model; $\lambda n=$ singular value for IPCA axis $n ; \gamma_{g n}=$ genotype eigenvector values for IPCA axis $\mathrm{n} ; \delta_{e n}=$ environment eigenvector values for IPCA axis $\mathrm{n}$ and $\rho_{g e}=$ the residuals

\section{AMMI stability value}

The principal component analysis (PCA) described by Purchase et al. (2000) was calculated as follows:

$A S V=\sqrt{\left[\frac{I P C A 1_{\text {Sumossquare }}}{I P C A 2_{\text {Sumossyure }}} \times\left(I P C A 1_{\text {score }}\right)\right]^{2}+\left(I P C A 2_{\text {Score }}\right)^{2}}$

Where, SSIPCA1/SSIPCA2 is the weight given to the IPCA1 value by dividing the
IPCA1 sum of squares by the IPCA2 sum of squares. The higher the IPCA score, either negative or positive, the more a genotype is specifically adapted to certain environments. Lower ASV scores indicate a more stable genotype across environments.

\section{Biplot analysis}

Biplot analysis is the most powerful interpretive tool of AMMI models. Biplots are graphs where aspects of both genotypes and environments are plotted on the same axis so that the inter-relationships can be visualized. There are two basic AMMI biplots- the AMMI1 where the main effects (genotype mean and environments) are plotted against each other and the AMMI2 where scores for IPCA 1 and IPCA 2 are plotted.

\section{RESULTS AND DISCUSSION}

The AMMI analysis of variance for rice grain yield $\left(t \mathrm{ha}^{-1}\right)$ of eight genotypes tested in four environments showed that the genotype (G), environment (E) and genotype $\times$ environment interaction (GEI) and its first two principal components (PCA1 and PCA2) were significant $(\mathrm{P}<$ 0.001 ). From $12.08 \%$ of the total sum of squares was attributed to environmental effects, only $26.13 \%$ to genotypic effects and $47.65 \%$ to genotype $\times$ environment interaction effects, which means that rice grain yield was contributed mainly by genotype $\times$ environment interaction effects followed by genotype and environment 
(Table 3). The environments were diverse and caused the greatest variation in grain yield. The genotype $\times$ environment interaction sum of squares was about 1.82 times larger than that for genotypes, which determined significant differences in genotypic response across environments. The first two principal components (PCA1 and PCA2) explained $78.50 \%$ and $14.30 \%$ of the GEI (Table 3). The mean grain yield of the eight genotypes ranged from 3.12 to $4.85 \mathrm{t} \mathrm{ha}^{-1}$. The highest yielding variety was BRRI dhan65, and the lowest one was BRRI dhan27 (Table 4). Among the four environments, the highest grain yield was obtained from environment E3 (Rajshahi; $\left.4.37 \mathrm{t} \mathrm{ha}^{-1}\right)$, and the lowest from $\mathrm{E} 1$ (Gazipur; $3.33 \mathrm{t} \mathrm{ha}^{-1}$ ).

In the AMMI-1 biplot (Fig. 1), the abscissa represents main effects ( $G$ and $E$ ) and its ordinate represents IPC1 scores. It thus provides a mean of simultaneously visualizing both mean performance $(\mathrm{G})$ and stability (IPC1) of genotypes. The IPC1 accounted for $78.50 \%$ of the GE interaction. The AMMI-1 biplot accounted for $87.45 \%$ of the total SS and is thus suitable for interpreting the GE interaction and main effects. Genotypes G6, G7 and G8 with mean yields greater than the overall mean

Table 3. AMMI analysis of variance for rice grain yield of eight genotypes tested in four environments.

\begin{tabular}{lcccccc}
\hline \multicolumn{1}{c}{ Source of variation } & $\mathrm{df}$ & Sum of squares & Mean squares & F value & P-value & Explained SS (\%) \\
\hline Environment & 3 & 14.12 & 4.71 & 20.29 & $<0.001$ & 12.08 \\
Replication (Environment) & 8 & 1.86 & 0.23 & 0.89 & 0.534 & 1.59 \\
Genotype & 7 & 30.54 & 4.36 & 16.66 & $<0.001$ & 26.13 \\
GE interaction & 21 & 55.69 & 2.65 & 10.13 & $<0.001$ & 47.65 \\
PC1 & 9 & 43.70 & 4.86 & 18.54 & $<0.001$ & 78.50 \\
PC2 & 7 & 7.97 & 1.14 & 4.35 & $<0.001$ & 14.30 \\
PC3 & 5 & 4.02 & 0.80 & 3.07 & $<0.05$ & 7.20 \\
Residual & 56 & 14.66 & 0.26 & & & 12.55 \\
Total & 95 & 116.86 & & & & \\
\hline
\end{tabular}

Table 4. Grain yield performance, PCA scores of eight genotypes and four environments.

\begin{tabular}{lccccc}
\hline Genotype & Code & Yield $\left(\mathrm{t} \mathrm{ha}^{-1}\right)$ & PC1 & PC2 & PC3 \\
\hline BR21 & G1 & 3.59 & 0.498 & 0.499 & -0.174 \\
BR24 & G2 & 3.58 & -0.059 & 0.730 & 0.234 \\
BR26 & G3 & 3.55 & 0.469 & -0.467 & 0.544 \\
BRRI dhan27 & G4 & 3.12 & -1.766 & -0.078 & -0.028 \\
BRRI dhan42 & G5 & 3.76 & 0.275 & 0.396 & 0.071 \\
BRRI dhan43 & G6 & 4.39 & 0.038 & -0.269 & 0.218 \\
BRRI dhan48 & G7 & 4.58 & 0.277 & -0.587 & -0.014 \\
BRRI dhan65 & G8 & 4.85 & 0.268 & -0.224 & -0.851 \\
Gazipur & E1 & 3.33 & 0.235 & -1.030 & -0.313 \\
Kushtia & E2 & 4.10 & 0.305 & 0.033 & 0.916 \\
Rajshahi & E3 & 4.37 & 1.057 & 0.687 & -0.440 \\
Rangpur & E4 & 3.91 & -1.597 & 0.310 & -0.162 \\
\hline
\end{tabular}




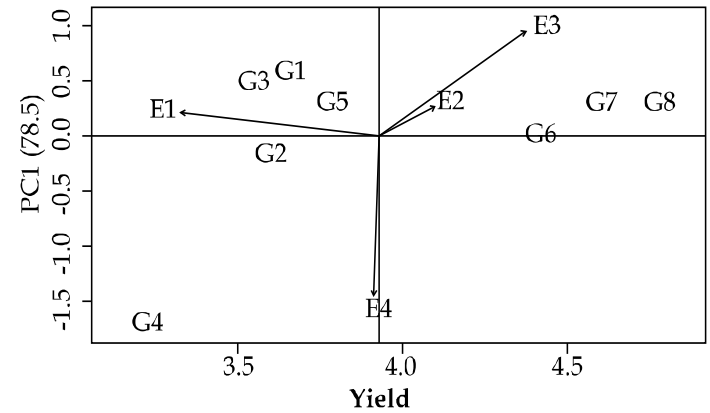

Fig. 1. Interaction of principal component analysis versus grain yield.

and low IPC1 scores had a high combination of yield and stable performances. They indicate that these genotypes are associated with adaptability and stability. The genotype G2 and G5 gave lower yield along with the IPCA1 score close to zero and it was adjudged as the stable genotype. The genotypes G1 and G3 were found to have below average yield and both IPCA1 score close to each other but tended to contribute more to GE interaction. The performances of these genotypes were not decent with respect to yield and stability. On the other hand, the genotype G4 with mean yields less than the overall mean and with the highest distance from the IPC1 $=0$ level, tended to contribute highly to GE interaction and accordingly can be regarded as the most unstable genotypes. Among the environments, E2 registered above average yield and had positive IPCA1 score i.e. had small interaction effects indicating that this environment was considered as the suitable environment and all the genotypes performed well in this location. Here the environment E1 was found to have below average yield but had positive IPCA1 score close to zero means favourable environment for all the genotype. And all the genotypes of the study can be grown in this environment. The unfavourable conditions in the E3 and E4 indicate that the genotypes were unstable under those environments.

Figure 2 shows the AMMI2 biplot for grain yield, which accounted for $92.8 \%$ of the $\mathrm{G} \times \mathrm{E}$ interaction. Since, PCA2 scores were also important $(14.30 \%$ of $\mathrm{G} \times \mathrm{E}$ SS) in explaining the genotype $\times$ environment interaction, the ballot of the first two PCAs was also used to demonstrate the relative magnitude of the GEI for specific genotypes and environments (Fig. 2). In the AMMI2 biplot points situated nearby to the origin with low scores for two IPCA1 and IPCA2 axes represent stable genotypes and environments. From the study environments E1, E3 and E4 had the highest distance from the origin, so these are sensitive to genotypes changes and have a large $\mathrm{G} \times \mathrm{E}$ interaction. On the other hand, E2 environment was found to be closest to the origin that represent stable environment and also larger mean yield than the average yield (Figs. 1 and 2). This environment showed the smallest scores, thus it has smallest GE interaction effect and were non-sensitive to change in different genotypes and environmental interactive factors. In case of E1 and E4 environments the mean yield less than the average yield and accordingly can be regarded as the most unstable environment. Also E3 situated at the moderate distance from the origin and showed both positive scores of IPCA1 and IPCA2. The specific adaptation indicates a high mean productivity of a genotype in a selected environment. For example, genotype G6, G7 and G8 are adapted to the environments E2 and the genotypes G3 and G7 are adapted to the environment E1, etc (Fig. 2). Regarding the environments, poor contributions were presented by the environments E1, E3 and E4 (Fig. 2). E3 gives the highest mean of productivity (4.37 $\left.\mathrm{t} \mathrm{ha}^{-1}\right)$ and $\mathrm{E} 1$ gives the lowest mean (3.33 $\left.\mathrm{t} \mathrm{ha}^{-1}\right)$. 


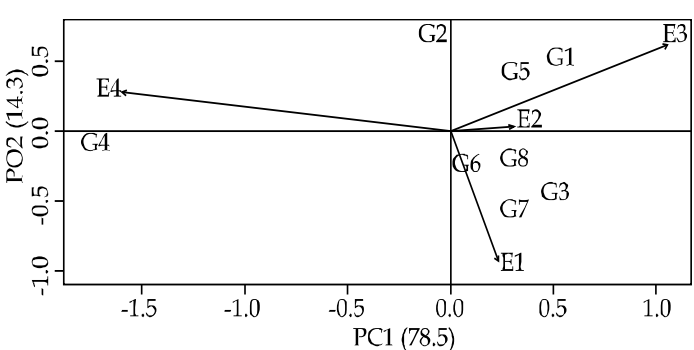

Fig. 2. PCA1 versus PCA2 for grain yield of genotypes.

\section{CONCLUSION}

The study revealed that yield was highly influenced by GE interactions followed by the differences among genotypic and environmental effects. Three high yielding genotypes including BRRI dhan65, BRRI dhan48 and BRRI dhan43 were found suitable across environments and considered ideal. Among the environments Kushtia registered above average yield and this environment was identified as the suitable environment for genotypes BRRI dhan43, BRRI dhan 48 and BRRI dhan65 due to stable yields.

\section{REFERENCES}

Awal, M A, M A B Siddique. 2011. Rice production in Bangladesh employing by ARIMA model. Bangladesh J. Agril. Res. 36 (1), 51-52.

BBS (Bangladesh Bureau of Statistics). 2018. Yearbook of Agricultural Statistics of Bangladesh. Government of Bangladesh.

BBS (Bangladesh Bureau of Statistics). 2018. National Accounts Statistics. Government of Bangladesh.

Berzsenyi, Z, Q L Dang. 2008. Effect of various crop production factors on the yield and yield stability of maize in a long-term experiment. Cereal Research and Community 36, 167-176.

Blanche, S B, H S Utomo, I Wenefrida, G O Myers. 2009. Genotype $\times$ Environment interactions of hybrid and varietal rice cultivars for grain yield and milling quality. Crop Science 49, 2011-2018.

BRRI (Bangladesh Rice Research Institute). 2018. Adhunik Dhaner Chash. BRRI, Gazipur, Bangladesh.
DAE (Department of Agriculture). 2018. Agricultural Dairy. Government of Bangladesh.

Dingkuhn, M, D Luquet, H Kim, L Tambour, A C Vidal. 2006. Eco meristem, a model of morphogenesis and competition among sinks in rice. Simulating genotype responses to phosphorus deficiency. Functional Plant Biology 33, 325-337.

Eberhart, S A and W A Russel. 1966. Stability parameters for comparing varieties. Crop Sci. 6: $36-40$

Gauch, H G. 1992. Statistical Analysis of Regional Yield Trials: AMMI Analysis of Factorial Designs, Elsevier Science Publishers, Amsterdam, the Netherlands.

Gauch, H G. 1993. Matmodel Version 2.0. AMMI and related analysis for two-way data matrices. Micro Computer Power, Ithaca, New York, USA.

Hasan, M J, M U Kulsum, M M Hossain, Z Akond and M M Rahman. 2014. Identification of stable and adaptable hybrid rice genotypes. SAARC J. Agri., 12 (2): 1-15.

HIES (Household Income and Expenditure Survey), 2010. Bangladesh Bureau of Statistics. Government of Bangladesh, Dhaka.

Kulsum, M U, M J Hasan, M N Haque, M S Uddin and K M Iftekharuddaula. 2015. Effect of genotype-environment interaction on grain yield of exotic rice (oryza sativa 1.) Hybrids. Bangladesh J. Bot. 44 (4): 507-514.

Lestari, A P, B Abdullah, A Junaedi and H Aswidinnoor. 2010. Yield stability and adaptability of aromatic new plant type (NPT) rice lines. Journal Agronomi Indonesia 38 (3), 199-204.

Lin, C S, M R Binns and L P Lefkovitch. 1986. Stability analysis: where do we stand? Crop Science 26, 894-900.

Lone, A A, P A Sofi, M Z Warsi and S H Wani. 2009. Stability analysis in maize (Zea mays L.) for anthesis silking interval and grain yield. Maize Genetics Cooperation Newsletter 83, 19.

Luthra, O P, R K Singh and S N Kakar. 1974. The stability of the twelve genotypes was evaluated. Theory and Applied Genetics 45, 143-149.

McLaren, C G and C Chaudhary. 1994. Use of additive main effects and multiplicative interaction models to analyze multi location rice variety trials. Paper presented at the FCSSP Conference, Puerton Princesa, Palawan, Philippines.

Messina, C, G Hammer, Z Dong, D Podlich, M Cooper. 2009. Modelling crop improvement in a 
$\mathrm{G} \times \mathrm{E} \times \mathrm{M}$ framework via gene-trait-phenotype relationships. In: Sadras, VO, Calderini, D. (Eds.), Crop physiology: Applications for Genetic Improvement and Agronomy. Elsevier, Netherlands, 235-265 p.

Mosavi, A A, N B Jelodar, K Kazemitabar. 2013. Environmental responses and stability analysis for grain yield of some rice genotypes. World Applied Sciences Journal 21 (1), 105-108.

Purchase, J L, H Hatting and C S V Deventer. 2000. Genotype $\times$ environment interaction of winter wheat (Triticum aestivum L.) in South Africa: П. Stability analysis of yield performance. South African Journal of Plant and Soil 17: 101-107.

Sreedhar, S, T R Dayakar and M S Ramesha. 2011. Genotype $\times$ Environment interaction and stability for yield and its components in hybrid rice cultivars (Oryza sativa L.). International Journal of Plant Breeding and Genetics 5(3), 194-208.

Tariku, S, T Lakew, M Bitew and M Asfaw. 2013. Genotype by environment interaction and grain yield stability analysis of rice (Oryza sativa L.) genotypes evaluated in north western Ethiopia. Net J. Agric. Sci. 1, 10-16.

Kulsum, M U, M J Hasan, M I Hossain and N M F Rahman. 2014. Stability for BRRI developed promising hybrid rice for yield and its related traits. J. Appl. Sci. and Agric., 9 (1): 56-62.

Yan, W. 2001. GGE biplot- a window application for graphical analysis of multi environmental data and other types of two-way data. Agron. J., 93. 1111-1118.

Zobel, $\quad$ R W, M J Wright and H G Jnr Gauch. 1988. Statistical analysis of a yield trial. Agronomy Journal, 80, 388-393. 